\title{
Testicular prostheses in patients with testicular cancer - acceptance rate and patient satisfaction
}

\author{
Klaus-Peter Dieckmann ${ }^{1 * \dagger}$, Petra Anheuser ${ }^{1 \dagger}$, Stefan Schmidt ${ }^{2}$, Benjamin Soyka-Hundt ${ }^{1}$, Uwe Pichlmeier ${ }^{3}$, \\ Philipp Schriefer ${ }^{4}$, Cord Matthies ${ }^{2}$, Michael Hartmann ${ }^{4}$ and Christian G Ruf ${ }^{2}$
}

\begin{abstract}
Background: The loss of a testicle to cancer involves much emotional impact to young males. Little is known about the number of patients with testicular germ cell tumour (GCT) who would accept a testicular prosthesis. Also, knowledge about the satisfaction of implant recipients with the device is limited.

Methods: A retrospective chart analysis was performed on 475 consecutive GCT patients. Prior to orchiectomy, all patients were offered prosthesis insertion. Acceptance of implant was noted along with age, clinical stage, histology and year of surgery. 171 implant recipients were interviewed using an 18 item questionnaire to analyze satisfaction with the prosthesis. Statistical analysis involved calculating proportions and $95 \%$ confidence intervals. Multivariate analysis was performed to look for interrelations between the various items of satisfaction with the implant.

Results: $26.9 \%$ of the patients accepted a prosthesis. The acceptance rate was significantly higher in younger men. Over-all satisfaction with the implant was "very high" and "high" in $31.1 \%$ and $52.4 \%$, respectively. $86 \%$ would decide again to have a prosthesis. Particular items of dis-satisfaction were: implant too firm (52.4\%), shape inconvenient (15.4\%), implant too small (23.8\%), position too high (30.3\%). Living with a permanent partner had no influence on patient ratings. Multivariate analysis disclosed numerous inter-relations between the particular items of satisfaction.

Conclusions: More than one quarter of GCT patients wish to have a testicular prosthesis. Over-all satisfaction with implants is high in more than $80 \%$ of patients. Thus, all patients undergoing surgery for GCT should be offered a testicular prosthesis. However, surgeons should be aware of specific items of dis-satisfaction, particularly shape, size and consistency of the implant and inconvenient high position of the implant within the scrotum. Appropriate preoperative counselling is paramount.
\end{abstract}

Keywords: Testicular cancer, Testicular prosthesis, Orchiectomy, Masculinity, Quality of life, Body appearance

\section{Background}

The loss of a testicle due to cancer has considerable impact on the sexual life and over-all quality of life in survivors of patients with testicular germ cell tumour (GCT) because this is felt to be a threat to masculinity by many patients [1]. That loss is associated with feelings of uneasiness or shame about impaired body appearance in one quarter of the patients and roughly one third of GCT patients do actually miss or have previously missed their lost testicle [2]. Not surprisingly, younger men perceive the loss of a testicle more often a humiliating situation than older men do [3]. From a

\footnotetext{
* Correspondence: DieckmannKP@t-online.de

${ }^{\dagger}$ Equal contributors

'Department of Urology, Albertinen-Krankenhaus Hamburg, Hamburg, Germany Full list of author information is available at the end of the article
}

practical point of view, replacement of a testicle by a testicular prosthesis is technically simple, and only few surgical complications are to be expected [4,5]. Generally, questions surrounding the quality of life have increasingly gained attention among physicians caring for GCT patients [6]. However surprisingly, despite the ever increasing total number of reports relating to GCT, the issue of testicular implants has been addressed only sporadically. The first testicular prosthesis was implanted in 1941 [7]. Technical refinements regarding the material of the device were reported subsequently [8] until the silicone-made testicular prosthesis was introduced in 1973 [9]. That type of implant is still in use with only few modifications made [10,11]. There are some reports on the technical feasibility of testicular 
prosthesis insertion and on surgical problems relating to this procedure [12-15], but very few studies have systematically explored the patient view on testicular implants. In particular, little information exists as to how many patients would accept an implant in the case of orchiectomy for GCT and how those having received such a device are satisfied with it. Remarkably, none of the current international guidelines on treatment of GCT address the option of prosthesis implantation subsequent to orchiectomy [16-19]. We retrospectively looked to our sample of testis cancer patients to find out how many of them accepted an implant and if there were any associations with age and oncological characteristics. Further, we asked recipients of testicular prostheses about their satisfaction with the implant using a questionnaire.

\section{Methods}

Since 1997, it was the policy of our department to offer the implantation of a testicular prosthesis to patients undergoing surgery for GCT and who were not older than 60 years. From January 1997 to June 2014 a total of 507 patients underwent inguinal orchiectomy for testicular cancer. We retrospectively analyzed the patient files and noted whether or not the patient had been offered and if so whether they had accepted a testicular prosthesis. To look for any association of prosthesis acceptance with clinical characteristics, the following parameters were registered additionally: patient's age, histology of GCT, and clinical stage. To look for any temporal association of implant acceptance, the year of orchiectomy was noted. 475 patients (293 pure seminoma, 183 nonseminoma) qualified for further analysis.

The patient perception of living with a testicular implant was studied by interviewing the recipients with a structured questionnaire after obtaining written informed consent from the patients. Only adult patients were asked to participate in the study. To obtain a sufficient number of patients for a meaningful statistical analysis, the questionnaire was sent to implant recipients of three Hamburg based testicular cancer units (Albertinen-Krankenhaus, BundeswehrKrankenhaus, Universitätsklinikum Eppendorf). Candidates for interview were defined by the diagnosis of unilateral testicular germ cell tumour and by having the implant for at least half a year and no longer than 10 years. The response rate was $41 \%$ and a total of 171 questionnaires were available for analysis. The questionnaire involved 18 questions (see Additional file 1) with multiple choice answers and one question with free-text answering. The study had been approved by the institutional ethical committee of the Theologisches Seminar Elstal (Wustermark).

\section{Statistical analysis}

The data of both parts of the study were filed in a commercially available system (Microsoft Excel) prior to further analysis. The final statistical analysis was accomplished by using descriptive statistical methods performed with the SAS software package (version 9.3, SAS Institute, Inc., Cary, NmC, USA) on Windows platform. To derive exact confidence intervals for multinominal parameters, StatXact (Version 9.0, Cytel Software Corporation) was applied. Pre-defined hypotheses were subjected to statistical analysis. For nominal variables, Chi-square tests were applied. Exact Cochran-Armitage trend tests were employed for testing ordered binominal populations and the exact Jonckhere Terpstra tests for doubly ordered contingency tables, respectively. Ordinal variables between two groups were tested using Mann-Whitney tests. For multivariable assessment of the probability of acceptance logistic regression models were derived [20].

\section{Results}

A total of 128 patients of the unselected GCT cohort accepted a testicular prosthesis (26.9\%). Tables 1 and 2 show the acceptance rates in subgroups and the associations with clinical parameters. The acceptance rate did not change over time. The only significant association was with age (Cochran Armitage Trend Test $\mathrm{p}=0.0058$ ). The acceptance rate was $30.5 \%$ in patients younger than

\section{Table 1 Acceptance rate of testicular prostheses in} unselected cohort of GCT patients

\begin{tabular}{llll}
\hline & Total & \multicolumn{2}{l}{ With prosthesis } \\
\cline { 3 - 4 } & $\mathbf{n}(\%)$ & $\mathbf{n}(\%)$ & $\mathbf{9 5 \%} \mathbf{C l}$ \\
\hline $\begin{array}{l}\text { Total sample } \\
\text { Histology* }\end{array}$ & $475(100)$ & $128(26.9)$ & $23.0 \% ; 31.2 \%$ \\
$\quad$ Seminoma & $293(100)$ & $81(27.6)$ & $22.6 \% ; 33.1 \%$ \\
$\quad$ Nonseminoma & $182(100)$ & $47(25.8)$ & $19.6 \% ; 32.8 \%$ \\
Clinical stage ${ }^{* *}$ & & & \\
CS1 & $313(100)$ & $91(29.1)$ & $24.1 \% ; 24.4 \%$ \\
CS 2 & $138(100)$ & $32(23.2)$ & $16.4 \% ; 31.1 \%$ \\
CS 3 & $24(100)$ & $5(20.8)$ & $7.1 \% ; 42.2 \%$ \\
Age at diagnosis & & & \\
$\leq 20$ years & $16(100)$ & $4(25.0)$ & $7.3 \% ; 52.2 \%$ \\
$>20-\leq 30$ years & $103(100)$ & $34(33.0)$ & $24.1 \% ; 43.0 \%$ \\
$>30-\leq 40$ years & $206(100)$ & $61(29.6)$ & $23.5 \% ; 36.4 \%$ \\
$>40-\leq 50$ years & $113(100)$ & $25(22.1)$ & $14.9 \% ; 30.9 \%$ \\
$>50-\leq 60$ years & $37(100)$ & $4(10.8)$ & $3.0 \% ; 25.4 \%$ \\
Treatment ${ }^{\#}$ & & & \\
$1997-2003$ & $143(100)$ & $35(24.5)$ & $17.7 \% ; 32.4 \%$ \\
$2004-2009$ & $167(100)$ & $55(32.9)$ & $25.9 \% ; 40.6 \%$ \\
$2010-2014$ & $165(100)$ & $38(23.0)$ & $16.8 \% ; 30.2 \%$ \\
\hline
\end{tabular}

*histology: chi-square test $\mathrm{p}=0.66$.

**clinical stage: Cochran-Armitage Trend Test $p=0.07$.

sage at diagnosis: Cochran-Armitage Trend Test $p=0.006$, significant.

\# episode of treatment: Cochran-Armitage Trend Test $p=0.38$.

Cl 95\% confidence intervals. 


\begin{tabular}{|c|c|c|c|c|}
\hline $\begin{array}{l}\text { Parameter } \\
\text { Age (years) }\end{array}$ & Odds ratio & \multicolumn{2}{|c|}{ 95\% Wald Cl } & $\frac{\text { p-value }}{0.05}$ \\
\hline$\leq 20$ vs. $>30-\leq 40$ & 1.06 & 0.31 & 3.62 & \\
\hline$>20-\leq 30$ vs. $>30-\leq 40$ & 1.28 & 0.75 & 2.17 & \\
\hline$>40-\leq 50$ vs. $>30-\leq 40$ & 0.64 & 0.37 & 1.11 & \\
\hline$>50-\leq 60$ vs. $>30-\leq 40$ & 0.28 & 0.09 & 0.82 & \\
\hline Histology & & & & 0.50 \\
\hline Seminoma yes vs. no & 0.84 & 0.52 & 1.38 & \\
\hline Clinical stage & & & & 0.33 \\
\hline CS2 vs. CS1 & 0.71 & 0.43 & 1.15 & \\
\hline CS3 vs. CS1 & 0.70 & 0.23 & 1.93 & \\
\hline Year of treatment & & & & 0.09 \\
\hline 2004 - 09 vs. 1997 - 2003 & 1.65 & 0.99 & 2.74 & \\
\hline 2010-14 vs. 1997 - 2003 & 1.06 & 0.61 & 1.82 & \\
\hline
\end{tabular}

*Wald chi square; CS clinical stage; Cl confidence intervals.

40 years while it was $19.3 \%$ in the older age group. The parameter "age" remained almost significant $(\mathrm{p}=0.0503)$ upon multivariate analysis.

The statistical analysis of the questionnaire was somewhat hampered by the fact that some of the 171 patients did not answer to every question. So, sample size varies with each question (Table 3). The majority of implant recipients $(77.4 \%)$ were living with a permanent partner and the majority had the device for more than 2 years (74.3\%). 4.8\% required additional surgery. To "look normal with regard to the genital region" was rated "extremely important" or "important" in 53\% and 32\% of patients, respectively. Accordingly, $98 \%$ of the responders regarded the preoperative offer of an implant important. However, preoperative counseling with respect to testicular prosthesis insertion was valued "too short" by $31 \%$ and even "insufficient" by $8.5 \%$. With respect to the physical appearance of the implant, $52.4 \%$ valued the consistency "too firm" and $15.4 \%$ rated the shape of the implant "not convenient" with most of the dissatisfied men saying it was "too round". 9.8\% sensed the implant as a foreign body. Size of the implant was regarded "too small" by $23.8 \%$ while $30.3 \%$ criticized a "too high" position of the implant within the scrotum.

Despite dissatisfaction with several particular items, the over-all satisfaction with the implant was very high and high in $31.1 \%$ and $52.4 \%$, respectively. Accordingly, $86.1 \%$ would opt again for receiving an implant in the case of orchiectomy.

Living with or without a permanent partner had no influence on any of the patient ratings. However, multivariate analysis disclosed several significant associations between the physical attributes of the implant (Table 4). Inappropriate size of the implant was associated with perceived excess weight of the device and with inconvenient shape, respectively. Inappropriate position within the scrotum correlated with insufficient weight of prosthesis. The appraisal "too firm" was associated with inconvenient shape and with inappropriate position. Overall satisfaction was significantly higher in patients having the prosthesis for more than two years $(\mathrm{p}=0.015$; exact Jonckhere-Terpstra Test). Over- all satisfaction was $54.5 \%$ in patients who required additional treatment, while it was $85.6 \%$ among those without such procedures ( $\mathrm{p}=<0.001$, exact Mann-Whitney Test). Likewise, $87.3 \%$ of the patients opting again for a prosthesis were (very well and well) satisfied while only $60.8 \%$ deciding against redoing the implant were so. Over-all satisfaction was significantly associated with appropriate size of the implant, as well as with shape and consistency (Table 5).

\section{Discussion}

Surprisingly few studies have so far explored patient attitudes to receiving a prosthesis to replace a testicle that has been lost to cancer. It is thus valuable to note that more than one quarter of GCT patients $(26.9 \%)$ in the present series decided to have such a device. Expectedly, testicular implants are more frequently requested by younger patients. This observation has already been made previously $[15,21,22]$ and it is also in close accordance with the experience that body appearance is of greater importance to younger men [3].

Adshead et al. noted lower acceptance rates in married men and in those living in steady relationship [23]. We could not directly confirm this observation because we did not look to the marital status of the patients in our retrospective analysis. The inverse association of steady relationship and prosthesis acceptance appears probable as older men are more frequently married or live in steady relationship than younger men.

The likelihood of accepting a prosthesis decreases with age and likewise with the probability of living in steady relationship. Clinical stage and histology of the GCT did not influence the decision to have an implant in the present study.

The acceptance rate of $26 \%$ in our series is somewhat lower than the rates of 55\% [15], 46\% [24], and 43\% [25] reported earlier. Our report is in line with the $24 \%$ rate found in a large and unselected GCT population from Swedish hospitals [3] and it is not significantly different from the rate of $30 \%$ reported in a British series [23]. The reasons for the large differences regarding the acceptance rates among the reported series remain elusive. Selection in favour of young patients [24] could represent one possible bias, and chance due to small sample size [25] another. A patient's wish to have a prosthesis is a complex decision [26]. As documented in a Swedish survey on survivors of GCT, 32\% of patients reported 
Table 3 Results of questionnaire regarding patients' satisfaction with testicular implant

\begin{tabular}{|c|c|c|c|c|}
\hline Question & Eligible (n) & Answer & (\%) & $95 \% \mathrm{Cl}$ \\
\hline Married & 167 & yes & 50.3 & $41.4 \% ; 59.2 \%$ \\
\hline Living with permanent partner & 164 & yes & 77.4 & $69.5 \% ; 84.0 \%$ \\
\hline \multirow[t]{3}{*}{ Time living with implant } & 168 & $<1$ year- 2 years $>2$ years & 14.9 & $9.3 \% ; 22.3 \%$ \\
\hline & & & 10.7 & $5.8 \% ; 17.4 \%$ \\
\hline & & & 74.4 & $65.7 \% ; 81.8 \%$ \\
\hline Additional surgery after implant insertion & 170 & yes & 4.7 & $2.1 \% ; 9.6 \%$ \\
\hline \multirow[t]{2}{*}{ Normal appearance with two testicles: important? } & 168 & very important & $53.6 \%$ & $44.1 \% ; 62.6 \%$ \\
\hline & & important & 31.3 & $23.2 \% ; 40.6 \%$ \\
\hline Being offered a prosthesis, preoperatively & 169 & important & 98.2 & $94.2 \% ; 99.6 \%$ \\
\hline \multirow[t]{2}{*}{ Size of the implant } & 164 & too large & 9.8 & $5.0 \% ; 16.3 \%$ \\
\hline & & too small & 23.8 & $16.3 \% ; 32.3 \%$ \\
\hline \multirow[t]{2}{*}{ Weight of the implant } & 166 & too heavy & 6.6 & $2.9 \% ; 12.5 \%$ \\
\hline & & Just right & 91 & $84.4 \% ; 95.2 \%$ \\
\hline Shape of implant & 169 & not right & 15.4 & $9.7 \% ; 22.5 \%$ \\
\hline Consistence of implant & 164 & too firm & 52.4 & $43.4 \% ; 61.1 \%$ \\
\hline Position of implant within scrotum & 165 & too high & 30.3 & $22.0 \% ; 39.6 \%$ \\
\hline \multirow[t]{3}{*}{ Any particular feeling with the implant } & 164 & convenient & 16.5 & $10.0 \% ; 24.6 \%$ \\
\hline & & inconvenient & 4.3 & $1.5 \% ; 9.7 \%$ \\
\hline & & strange & 9.1 & $4.6 \% ; 16.0 \%$ \\
\hline Problems with implant during physical exercise & 164 & no & 92.1 & $85.8 \% ; 96.1 \%$ \\
\hline Concerns about future problems with the implant & 164 & no & 89.0 & $82.7 \% ; 93.6 \%$ \\
\hline \multirow[t]{2}{*}{ Counseling before implant placement } & 164 & too short & 31.1 & $22.7 \% ; 40.5 \%$ \\
\hline & & Insufficient & 8.5 & 4.2\%: $14.9 \%$ \\
\hline After all, would you have an implant again? & 165 & yes & 86.1 & $79.1 \% ; 91.4 \%$ \\
\hline \multirow[t]{4}{*}{ Over-all satisfied with implant } & 164 & very well & 31.1 & $22.2 \% ; 41.0 \%$ \\
\hline & & satisfied & 52.4 & $42.1 \% ; 62.4 \%$ \\
\hline & & just so & 12.2 & $6.5 \% ; 20.0 \%$ \\
\hline & & no & 4.3 & $7.4 \% ; 1.2 \%$ \\
\hline
\end{tabular}

feelings of loss and uneasiness or even shame secondary to the excision of a testicle. Acceptance rates of testicular prostheses are in close accordance with the prevalence of feelings of reduced masculinity secondary to orchiectomy.

As revealed in the second part of the present study, preoperative counselling is highly valued by the patients. Thus, the way and extent of professional advice prior to orchiectomy for TC will probably represent one cornerstone in patient decision-making regarding testicular implants [27].

In contrast to other reports, we did not find a trend to higher acceptance rates in recent years [3,24].

With regard to surgical complications, $4.7 \%$ of our patients required additional surgery. This result is well in line with the previously reported incidence of surgical complications of $2.6 \%$ to $8 \%$ following testicular prosthesis insertion $[4,14,15,28-30]$ and noteworthy, it is not higher than the $8 \%$ complication rate encountered after inguinal orchiectomy [31]. We did not experience ruptures of prosthesis or spontaneous extrusion but we did replace three devices because of shrinkage (Figure 1).

The over-all aesthetic results of testicular implants are far from ideal and this is probably the most important result of the present study. Dissatisfaction mostly relates to consistency (too firm), inappropriate size (too small), shape (too round), and to the position within the scrotum (too high). As revealed by multivariate analysis, there are numerous cross-associations between these items of satisfaction. Noteworthy, most of the previous studies reported very similar results (Table 6) [21,23,24,28,32,33]. Only one study from France revealed a somewhat higher degree of satisfaction with the particular aesthetic results [34]. The reasons for unfavourable aesthetic outcome are probably 
Table 4 Significant associations between various items of satisfaction with prosthesis

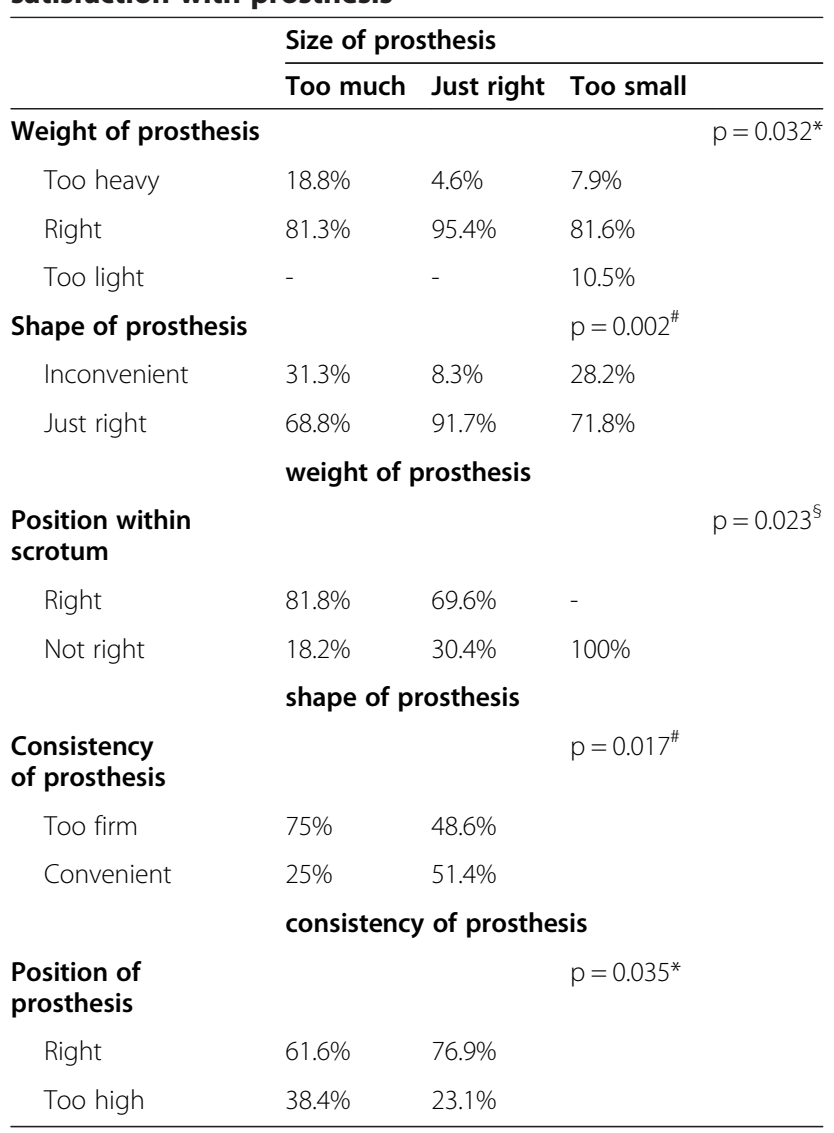

*Exact Jonckhere Terpstra test.

"chi square test.

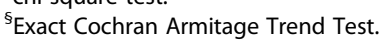

three-fold: iatrogenic (i.e. physician-made), manufacturermade, and nature-related. Consistency (too firm) and shape (too round) are probably related to technical and economic aspects of the manufacturing process but (hopefully), improvement should be possible as soon as manufacturing companies acknowledge the problem. Inappropriate size of implants appears to be an avoidable problem because it is the surgeon's duty to insert the bestfitting prosthesis intra-operatively. A 33\% dissatisfaction rate regarding the size (too small and too large) of the implants as noted in our series is rather surprising because, it is quite simple to select the appropriate size of the device from three or four available sizes. Yet, four previous studies also reported a very similar degree of dissatisfaction with size indicating that this kind of criticism is not uncommon. Dissatisfaction with size is much influenced by the patient's emotional appraisal of the implant. It is likely that dissatisfaction with prosthetic size is based on both, surgeon-related and patient-related misconceptions. To minimize such discontent, patients should be invited to actively participate in preoperative decision-making upon implant-size.

The inconvenient position of many of the implants (mostly too high within the scrotum) is probably related to two reasons. First, it could be a surgical failure to create a scrotal pouch not large enough to host the implant. The proper surgical procedures have been extensively reviewed $[24,35]$. However, inescapable biological processes i.e. tissue reactions to the synthetic material introduced into the scrotal cavity do possibly account for shrinkage of the scrotal wall and thus cause upward migration of the prosthesis. Analogous scarring reactions are known from breast implants [36]. It is thus paramount for the surgeon to both, employ the appropriate surgical technique to ensure the right position of the implant and to advise the patient preoperatively about biological processes that may cause inadvertent high position. Noteworthy, inappropriate high scrotal position of implants has been observed in $27-39 \%$ by two previous studies $[21,23]$. Positioning of the prosthesis appears to be a major problem and every surgeon performing such operations should be aware of the issue [37].

Table 5 Significant associations of over-all satisfaction with particular items of patients' satisfaction

\begin{tabular}{|c|c|c|c|c|c|c|}
\hline & Over-all sa & with tes & lant & & & \\
\hline & Very well & Well & Just so & Not much & Not at all & \\
\hline Size & & & & & & $p<0.001^{*}$ \\
\hline Too large & $7.8 \%$ & $13.3 \%$ & - & - & $33 \%$ & \\
\hline Right & $82.4 \%$ & $65.1 \%$ & $31.6 \%$ & $100 \%$ & - & \\
\hline Too small & $9.8 \%$ & $21.7 \%$ & $68.4 \%$ & - & $66.6 \%$ & \\
\hline Shape & & & & & & $p=0.001^{* *}$ \\
\hline Inconvenient & $5.9 \%$ & $14.0 \%$ & $35.0 \%$ & - & $66.7 \%$ & \\
\hline Convenient & $94.1 \%$ & $86.0 \%$ & $65.0 \%$ & $100 \%$ & $33.3 \%$ & \\
\hline Consistence & & & & & & $p<0.001^{* *}$ \\
\hline Too firm & $20.0 \%$ & $62.8 \%$ & $75.0 \%$ & $100 \%$ & $100 \%$ & \\
\hline Convenient & $80.0 \%$ & $37.2 \%$ & $25.0 \%$ & - & - & \\
\hline
\end{tabular}

All numbers represent percentages, ${ }^{*}$ Jonckhere-Terpstra Test, ${ }^{* *}$ Cochran-Armitage Trend Test. 


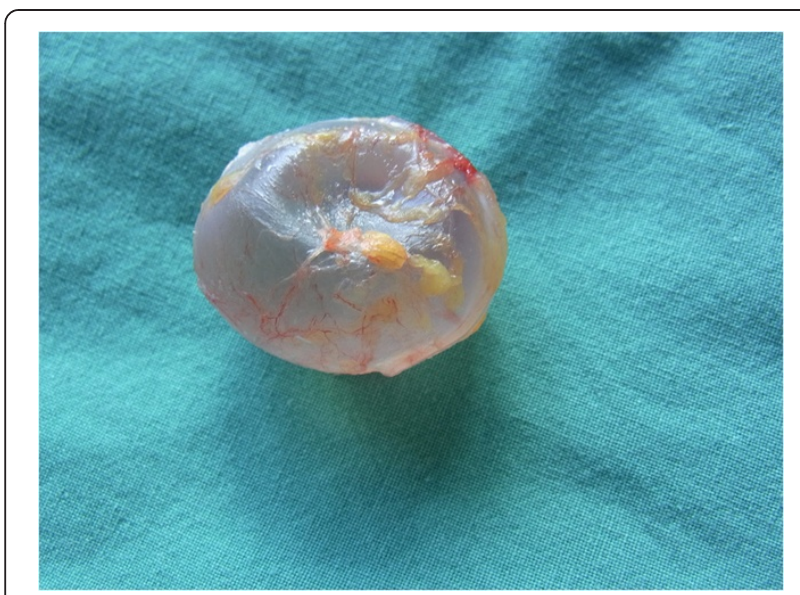

Figure 1 Silicone testicular prosthesis removed from scrotum because of shrinkage: note prune-like appearance of the device.

The answers to the more general questions of the questionnaire indicated a high rate of over-all contentment with the implant. No more than $10 \%$ of patients are concerned about potential health problems originating from the implant. Only few patients complained of inconvenient feelings with the implant (3.7\%). Some bother with the device upon physical activity was reported by $8.6 \%$ which is less than the $15 \%$ rate reported previously [21]. Accordingly, the over-all satisfaction rate is $83 \%$ (very high and high satisfaction). But noteworthy, over-all satisfaction is significantly influenced by contentment with the particular items of size, shape and consistency of the implant.

$86 \%$ of patients would decide again to have a prosthesis. This rate is identical to the result reported by Yossepowitch et al. [21] and it is similar to other studies reporting rates of slightly more than $90 \%$ [23,24,28,32-34] (Table 6).
Limitations of our study include the lack of a control group of patients who declined the offer of a prosthesis. Exploring the particular reasons for deciding against a prosthesis could aid in obtaining a clearer image of young men's emotions when they are confronted with the necessity of losing a testicle to cancer. Another drawback could be the lack of information regarding the manufacturer of the prostheses. Thus, relating specific items of dissatisfaction to the products of particular companies is not possible. On the other hand, strengths of our investigation include, first, the multicentric method of obtaining data on patients' perception of testicular implants and second, the investigation of the largest patient sample studied for this purpose to date. The latter two issues probably aid to keep selection bias low. The employment of multivariate statistical methods to reveal cross-associations of various items of satisfaction with implants is perhaps another strength of the present study.

\section{Conclusions}

More than one quarter of all testis cancer patients wish to receive a prosthesis to replace the excised testicle. Over-all satisfaction with the testicular implant is very high. All patients undergoing surgery for testis cancer should be advised about the availability of a testicular implant. However, it must be noted that there is considerable dissatisfaction with several particular attributes of the implants, e.g. shape, consistency, size, and high intrascrotal position. Urologic surgeons performing prosthesis insertion should be aware of these issues. Appropriate preoperative counselling with participation of the patient upon selection of implant size is paramount.

Table 6 Survey of the literature - patients' satisfaction with testicular implants

\begin{tabular}{|c|c|c|c|c|c|c|c|c|c|c|c|}
\hline Author & Year & Country & (n) & Method & $\begin{array}{l}\text { Over-all } \\
\text { satisfaction }\end{array}$ & $\begin{array}{l}\text { Have it } \\
\text { again }\end{array}$ & Shape & Position & Size & Consistency & Other \\
\hline \multirow[t]{2}{*}{ Petersen [24] } & 1992 & Ger & 119 & I & $93 \%$ & $93 \%$ & - & high $11 \%$ & $19 \%$ too large & $10 \%$ too firm & - \\
\hline & & & & & & & & & $14 \%$ too small & & \\
\hline Lynch [32] & 1992 & UK & 19 & $\mathrm{Q}$ & $79 \%$ & $95 \%$ & - & - & - & - & - \\
\hline Incrocci [33] & 2001 & $\mathrm{NL}$ & 22 & Q & $95 \%$ & $95 \%$ & - & - & - & 29\% inconvenient & - \\
\hline Adshead [22] & 2001 & UK & 71 & Q & $73 \%$ & $90 \%$ & $\begin{array}{l}32 \% \text { not } \\
\text { right }\end{array}$ & $27 \%$ not right & $37 \%$ inconvenient & - & $\begin{array}{l}30 \% \text { weight } \\
\text { inconvenient }\end{array}$ \\
\hline Boy [28] & 2002 & Ger & 39 & Q & $97 \%$ & - & - & $3 \%$ too high & $36 \%$ not right & $3 \%$ too firm & $\begin{array}{l}\text { partners' } \\
\text { rating: } 55 \% \\
\text { satisfied }\end{array}$ \\
\hline Xylinas [34] & 2008 & $\mathrm{~F}$ & 63 & $\mathrm{Q}$ & $96 \%$ & $96 \%$ & $\begin{array}{l}12 \% \text { not } \\
\text { right }\end{array}$ & $3 \%$ not right & $5 \%$ too small & $12 \%$ too firm & $2 \%$ too cold \\
\hline $\begin{array}{l}\text { Yossepowitch } \\
{[21]}\end{array}$ & 2011 & Isr & 86 & 1 & $88 \%$ & $86 \%$ & - & $39 \%$ too high & $27 \%$ not right & $73 \%$ too firm & $\begin{array}{l}\text { after } 2005 \\
\text { better results }\end{array}$ \\
\hline
\end{tabular}

I interview; Q questionnaire. 


\section{Additional file}

\section{Additional file 1: Questionnaire.}

\section{Competing interests}

The authors declare that they have no competing interests.

\section{Authors' contributions}

KPD conceived the study, designed the study, made substantial contributions to analyzing and interpreting the data, main contributor to drafting of manuscript. PA contributed to patient enrolment, made substantial contributions to analyzing and interpreting the data, coordinated multicentric data collection. SS contributed substantially to patient enrolment, contributed to drafting of manuscript, BSH contributed substantially to patient enrolment, made substantial contributions to analyzing and interpreting the data. UP contributed to designing of the study, carried out the statistical analysis, contributed to drafting and revising the manuscript. PS contributed substantially to patient enrolment, contributed in analyzing data. CM contributed to conceiving and designing of the study, contributed to patient enrolment, contributed to coordination of multicentric data collection. $\mathrm{MH}$ contributed to patient enrolment, contributed to drafting and critically revising the manuscript. CGR participated in designing of the study and contributed substantially to establishing of the questionnaire, contributed to analyzing data, contributed to drafting of manuscript. All authors read and approved the final manuscript.

\section{Acknowledgements}

Dr. Olaf Netzband and Raphael Ikogho substantially contributed to recruitment of patients.

\section{Author details}

${ }^{1}$ Department of Urology, Albertinen-Krankenhaus Hamburg, Hamburg, Germany. ${ }^{2}$ Department of Urology, Bundeswehrkrankenhaus Hamburg, Hamburg, Germany. ${ }^{3}$ Institute of Medical Biometry and Epidemiology, Universitätsklinikum Eppendorf, Hamburg, Germany. ${ }^{4}$ Department of Urology, Universitätsklinikum Eppendorf, Hamburg, Germany.

\section{Received: 25 October 2014 Accepted: 20 February 2015}

Published online: 13 March 2015

\section{References}

1. Rossen P, Pedersen AF, Zachariae R, von der Maase H. Sexuality and body image in long-term survivors of testicular cancer. Eur J Cancer. 2011;48(4):571-8

2. van Basten JP, Jonker-Pool G, van Driel MF, Sleijfer DT, van de Wiel HB, Mensink HJ, et al. Fantasies and facts of the testes. Br J Urol. 1996;78(5):756-62.

3. Skoogh J, Steineck G, Cavallin-Ståhl E, Wilderäng U, Håkansson UK, Johansson $B$, et al. Feelings of loss and uneasiness or shame after removal of a testicle by orchidectomy: a population-based long-term follow-up of testicular cancer survivors. Int J Androl. 2011;34(2):183-92

4. Marshall S. Potential problems with testicular prostheses. Urology. 1986:28(5):388-90

5. Beer M, Kay R. Testicular prostheses. Urol Clin North Am. 1989;16(1):13313-8.

6. Kim C, McGlynn KA, McCorkle R, Erickson RL, Niebuhr DW, Ma S, et al. Quality of life among testicular cancer survivors: a case-control study in the United States. Qual Life Res. 2011:20(10):1629-37.

7. Girdansky J, Newman HF. Use of a vitallium testicular implant. Am J Surg 1941:53:514.

8. Prentiss RJ, Boatwright DC, Pennington RD, Hohn WF, Schwarzt MH. Testicular prosthesis: materials, methods and results. J Urol. 1963:90(2):208-10.

9. Lattimer JK, Vakili BF, Smith AM, Morishima A. A natural-feeling testicular prosthesis. J Urol. 1973;110(1):81-3.

10. Rosen JS, Benson RCJ. Testicular prostheses. Semin Urol. 1984;2(3):176-9.

11. Böhm WD, Biedermann M, Hackel W, Baumann I, Knoch HG. Hodenprothesen-Chirurgie. Ergebnisse einer ambulanten klinischen Prüfstudie. Z Urol Nephrol. 1989;82:253-8.

12. Bodiwala D, Summerton DJ, Terry TR. Testicular prostheses: development and modern usage. Ann R Coll Surg Engl. 2007;89(4):349-53.

13. Weissbach $L$, Janssen PL, Bach D. Die Implantation von Hodenprothesen unter Berücksichtigung psychischer Aspekte. Urologe A. 1979;18(3):151-6.
14. Herrinton L, Brox T, Greenland S, Finkle WD, Cattolica E, Shoor S. Regarding: a cohort study of systemic and local complications following implantation of testicular prostheses. Ann Epidemiol. 2003;13(1):73-7.

15. Robinson R, Tait C, Clarke N, Ramani V. Is it safe to insert a testicular prosthesis at the time of radical orchidectomy for testis cancer - an Audit of 904 Men Undergoing Radical Orchidectomy. BJU Int 2014, Aug 28. doi:10.1111/bju.12920. [Epub ahead of print].

16. Albers P, Albrecht W, Algaba F, Bokemeyer C, Cohn-Cedermark G, Fizazi K, et al. EAU guidelines on testicular cancer: 2011 update. Eur Urol. 2011;60(2):304-19.

17. Oldenburg J, Fosså SD, Nuver J, Heidenreich A, Schmoll HJ, Bokemeyer C, et al. Testicular seminoma and non-seminoma: ESMO Clinical Practice Guidelines for diagnosis, treatment and follow-up. Ann Oncol. 2013;24 Suppl 6:vi125-32

18. Beyer J, Albers P, Altena R, Aparicio J, Bokemeyer C, Busch J, et al. Maintaining success, reducing treatment burden, focusing on survivorship: highlights from the third European consensus conference on diagnosis and treatment of germ-cell cancer. Ann Oncol. 2013;24(4):878-88.

19. Motzer R, Agarwal N, Beard C, Bhayani S, Bolger GB, Buyyounouski MK, et al. Testicular cancer. J Natl Compr Canc Netw. 2012;10(4):502-35.

20. Armitage $P$, Berry G, Matthews JNS. Statistical methods in medical research 4th ed. Oxford: Blackwell Scientific; 2002

21. Yossepowitch O, Aviv D, Wainchwaig L, Baniel J. Testicular prostheses for testis cancer survivors: patient perspectives and predictors of long-term satisfaction. J Urol. 2011;186(6):2249-52.

22. Schmidt S, Wagner W, Ruf CG. Evaluation der persönlichen Entscheidungskriterien für oder gegen die Implantation einer Hodenprothese. J Reproduktionsmed Endokrinol. 2013;10(5):309. Abstract.

23. Adshead J, Khoubehi B, Wood J, Rustin G. Testicular implants and patient satisfaction: a questionnaire-based study of men after orchidectomy for testicular cancer. BJU Int. 2001;88:559-62.

24. Petersen W, Hartmann M. Erfahrungen mit Hodenprothesen. Sexualmedizin. 1992:21:168-72

25. Gritz ER, Wellisch DK, Wang HJ, Siau J, Landsverk JA, Cosgrove MD. Long-term effects of testicular cancer on sexual functioning in married couples. Cancer. 1989;64(7):1560-07.

26. Chapple A, McPherson A. The decision to have a prosthesis: a qualitative study of men with testicular cancer. Psychooncology. 2004;13:654-64.

27. Rieker PP. How should a man with testicular cancer be counselled and what information is available to him? Semin Urol Oncol. 1996;14:17-23.

28. Boy D, Carl P. Akzeptanz von Silikonhodenprothesen im Langzeitverlauf. Urologe A. 2002;41:462-9.

29. Turek PJ, Master VA, Group TPS. Safety and effectiveness of a new saline filled testicular prosthesis. J Urol. 2004;172(4 Pt 1):1427-30.

30. Auberget JL, Bourlaud G, Timbal Y. Testicular prosthesis. Study of complications, apropos of 63 cases].[Article in French]. J Urol (Paris). 1989;95(8):505-6.

31. Anheuser P, Kranz J, Will J, Dieckmann KP. Complications associated with inguinal orchiectomy and scrotal orchiectomy].[Article in German]. Urologe A. 2014;53(5):676-82

32. Lynch MJ, Pryor JP. Testicular prostheses: the patient's perception. Br J Urol. 1992;70:420-2

33. Incrocci L, Bosch JL, Slob AK. Testicular prostheses: body image and sexual functioning. BJU Int. 1999;84:1043-5

34. Xylinas E, Martinache G, Azancot V, Amsellem Ouazana D, Saighi D, Flam T, et al. Testicular implants, patient's and partner's satisfaction: a questionnairebased study of men after orchidectomy].[Article in French]. Prog Urol. 2008;18(13):1082-6.

35. Lawrentschuk N, Webb DR. Inserting testicular prostheses: a new surgical technique for difficult cases. BJU Int. 2005;95:1111-4.

36. Zahavi A, Sklair ML, Ad-El DD. Capsular contracture of the breast: working towards a better classification using clinical and radiologic assessment. Ann Plast Surg. 2006;57(3):248-51

37. Foster RS. Role of urologist in testis cancer management. Editorial Comment. J Urol. 2013;186:1251. 